\title{
Research through design as a method for interaction design research in $\mathrm{HCl}$
}

\author{
John Zimmerman, Jodi Forlizzi, Shelley Evenson \\ Human-Computer Interaction Institute and The School of Design \\ Carnegie Mellon University \\ \{johnz, forlizzi, evenson\}@andrew.cmu.edu
}

\begin{abstract}
For years the HCI community has struggled to integrate design in research and practice. While design has gained a strong foothold in practice, it has had much less impact on the HCI research community. In this paper we propose a new model for interaction design research within HCI. Following a research through design approach, designers produce novel integrations of HCI research in an attempt to make the right thing: a product that transforms the world from its current state to a preferred state. This model allows interaction designers to make research contributions based on their strength in addressing under-constrained problems. To formalize this model, we provide a set of four lenses for evaluating the research contribution and a set of three examples to illustrate the benefits of this type of research.
\end{abstract}

\section{Author Keywords}

design, interaction design, interaction design research, HCI research, research through design, wicked problems, design theory, design method

\section{ACM Classification Keywords}

H5.2. User Interfaces: Theory and methods.

\section{INTRODUCTION}

In recent years we have both witnessed and participated in the struggle as several academic institutions have attempted to integrate design, with technology and behavioral science in support of HCI education and research. While there has been great excitement about the benefits integrating design can bring, we quickly realized that no agreed upon research model existed for interaction designers to make research contributions other than the development and evaluation of new design methods. Over the last two years we have undertaken a research project to (i) understand the nature of the relationship between interaction design and the HCI research community, and (ii) to discover and invent methods for interaction design researchers to more effectively participate in $\mathrm{HCI}$ research.

Through our inquiry we learned that many HCI researchers commonly view design as providing surface structure or decoration. In addition, we lack a unified vision of what design researchers can contribute to HCI research. This lack of a vision for interaction design research represents a lost opportunity for the HCI research community to benefit from the added perspective of design thinking in a collaborative research environment. The research community has much to gain from an added design perspective that takes a holistic approach to addressing under-constrained problems.

To address this situation, this paper makes two contributions: (i) a model of interaction design research designed to benefit the HCI research and practice communities, and (ii) a set of criteria for evaluating the quality of an interaction design research contribution. The model is based on Frayling's research through design [14], and it stresses how interaction designers can engage "wicked problems" [21]. What is unique to this approach to interaction design research is that it stresses design artifacts as outcomes that can transform the world from its current state to a preferred state. The artifacts produced in this type of research become design exemplars, providing an appropriate conduit for research findings to easily transfer to the HCI research and practice communities. While we in no way intend for this to be the only type of research contribution interaction designers can make, we view it as an important contribution in that it allows designers to employ their strongest skills in making a research contribution and in that it fits well within the current collaborative and interdisciplinary structure of $\mathrm{HCI}$ research

\section{Definitions}

As we conducted this inquiry, we quickly realized that within both the HCI and design communities there is an inconsistent and confusing use of the following terms. Therefore, below we provide a set of definitions for these terms with respect to this paper.

Designer. Using such a generic term is a challenge at best. At CHI 2006's SIG: "The CHI Design Community", Bill Buxton sarcastically claimed that if everyone is a designer because they select their own clothes, then everyone is also a mathematician, because we all count our change. His 
comment captures what a loaded term "designer" is. Within the HCI community, it is quite common for people to use the term design to mean HCI practice and to use the term designer to mean an HCI practitioner. In this case a designer might be an interaction designer, a usability engineer, a software architect, a software developer, etc. However, in the design community, the term designer is generally used to refer to someone who has had training or extensive practical experience in a discipline such as architecture, product design, graphic design, or interaction design. As we use the term designer in this paper, we are following the convention of the design community.

Design research. In the HCI community and in the design practice community, the term design research is generally used to refer to the upfront research practitioners do to ground, inform, and inspire their product development process. However, in the design research community, including institutions such as the Design Research Society, the term design research implies an inquiry focused on producing a contribution of knowledge. This paper follows the convention of the design researchers, and we intend the term design research to mean an intention to produce knowledge and not the work to more immediately inform the development of a commercial product.

Design thinking. This term is often used to describe what designers bring to problem solving and to rationalize why designers need to be included in a project or process; however, it is rarely defined. In some respects its ambiguity is part of its strength, allowing it to be the right thing at the right time. In terms of this paper, we mean the application of a design process that involves grounding - investigation to gain multiple perspectives on a problem; ideationgeneration of many possible different solutions; iterationcyclical process of refining concept with increasing fidelity; and reflection.

In the next section, we provide an overview of our research and methodology in constructing this model. We highlight the findings from our literature review, and detail the evolving history of design in HCI and of interaction design research and its impact on the HCI community in order to situate our contribution within the frameworks of $\mathrm{HCI}$ research and design research. We then describe the model, detail how it produces knowledge, and discuss how it produces benefits for both the HCI practice and research communities. We formalize the model by describing four lenses to evaluate the quality of an interaction design research contribution. Finally, we illustrate how three examples of interaction design research can be evaluated by the criteria described here.

\section{METHODOLOGY}

Our methodology included a literature review focusing on design in HCI and on models of design research; a workshop on the relationship between design and HCI; semi-structured interviews with leading HCI researchers and leading interaction designers in academia and industry; synthesis of the findings from the literature and interviews, and the construction of a new model of design research; iterative evaluations of this model with leading HCI researchers and designers; and finally, a refinement that produced the current model.

\section{Literature review}

We reviewed the design research literature to understand historical and currently proposed models of design research and more specifically, interaction design research. In addition, we reviewed literature from the HCI community discussing the role of design.

\section{CHI 2004 workshop}

In 2004 we conducted a workshop at the CHI conference in Vienna, focusing on clarifying the relationship between HCI and design. The workshop, had 22 participants from both academia and industry and from a range of backgrounds including computer science, behavioral science, and interaction design and explored two distinct but complimentary tracks: (i) role of design in $\mathrm{HCI}$ education and role of HCI in design education, and (ii) the role of interaction design research in HCI. Outcomes from this workshop helped frame our focus on the need to define models of design research in $\mathrm{HCI}$ and motivated us to engage the broader HCI practice and research community in a discussion of what these might be.

\section{Interviews}

We conducted semi-structured interviews with nine leading academic HCI researchers accompanied by one of their graduate students. During the interview, we asked about their ideas of what design is and what design research is in terms of HCI research. We chose to interview the leaders with a graduate student for two reasons. First, we thought a process of co-discovery would help us elicit better information during the interview. Second, we wanted to see if the students, who were much newer to HCI and were being educated in a multidisciplinary environment that includes behavioral science, computer science, and interaction design, had a substantially different view of design than their advisors, who had all been trained in a single discipline.

We also interviewed six leading interaction designers. Three held senior academic positions, and three held industry positions including head of design at a consumer electronics company, a design researcher at a well-known technology research company, and the principal of a design consultancy. In these interviews, in addition to collecting information on the evolution of their career in HCI, we probed on the nature of the relationship between design and HCI and on what they saw as the important models of design research with respect to the HCI research community.

\section{Synthesis, analysis, and iterative modeling}

After generating a preliminary model, we iteratively evaluated the model through presentations and discussions. One included a large group of HCI researchers, none of 
whom had training in design. In addition, we held four oneon-one presentations of the model along with other research models including Dick Buchanan's model of design research [4] and Daniel Fallman's model of researchoriented design and design-oriented research [12,13]. These one-on-one interviews included a senior HCI practitioner, a leading design researcher in $\mathrm{HCI}$, and two leading $\mathrm{HCI}$ researchers from industry. The one-on-one discussions allowed for more free-form feedback on our model and a chance for the interviewee to participate in rapid redesign. The large discussion was particularly beneficial in that it engaged the entire group in a discussion of what design research meant to their specific discipline within HCI and a discussion of what design does and should mean within the HCI research community.

\section{LITERATURE REVIEW}

Our literature review, meant to ground our inquiry, focused on the history of the emerging field of design research, the role of design in HCI, and the role of the designed artifact.

\section{Design Research}

The emergence of design research as a separate activity from design practice grew out of the need to formally address the increasing complexity of systems designers were being asked to create [3]. The increasing complexity of products such as battleships, airplanes, and rockets created a need for new design methods that were more predictable and more collaborative. The design methods movement grew out of this need, and generated the first cohort of design researchers focusing on the development of knowledge instead of artifacts for consumption.

Within the design research community, there has been an ongoing tension around the relationship between design and science [8]. Motivation for a scientific framing came from sources such as Buckminster Fuller's call “...for a 'design science revolution' based on science, technology, and rationalism..." [8 p.50], and from Herbert Simon's call for the study of science of design to help more liberally educate scientists and engineers in his book Sciences of the Artificial [23]. In this case the science can be a scientific study of how designers work or the use of scientific knowledge and methods in a rational practice of design [8].

In adding to the research discussion of design methods, Donald Schön introduced the idea of design as a reflective practice where designers reflect back on the actions taken in order to improve design methodology [22]. While this may seem counter to the science of design, where the practice of design is the focus of a scientific inquiry, several design researchers have argued that reflective practice and a science of design can co-exist in harmony $[8,5]$.

In reaction to the casting of design as a science and also in response to systems engineers' inability to apply scientific methods to address social problems such as urban crime, Horst Rittel and Melvin Webber proposed the concept of a "Wicked Problem," a problem that because of the conflicting perspectives of the stakeholders cannot be accurately modeled and cannot be addressed using the reductionist approaches of science and engineering [21]. They argued that many problems can never be accurately modeled, thus an engineering approach to addressing them would fail. This work pointed to an opportunity for design research to provide complementary knowledge to the contributions made by scientists and engineers through methods unique to design and design processes.

Design researchers describe their work as “...the study, research, and investigation of the artificial made by human beings, and the way these activities have been directed either in academic studies or manufacturing organizations." [3 p 16.] The focus of this work has been on a study of design in order to improve the process and on the analysis of design artifacts in order to generate theories that unite related methods of addressing design challenges. In general, this design research scholarship has not focused on the outcome (artifacts) of making as a design contribution.

\section{The Role of Design in $\mathrm{HCl}$}

In the early days, the term "design" within the HCI community meant usability engineering: "...the process of modeling users and systems and specifying system behavior such that it fitted the users' tasks, was efficient, easy to use and easy to learn." [26 p.1]. Over time, trained designers began working with software developers, bringing skills in visual hierarchy, navigation, color, and typography they had developed designing printed artifacts. Jonas Löwgren labeled the process they brought to interaction design as "creative design" to distinguish it from the engineering approach [16]. In engineering design, developers created software to meet a specification, and in creative design, designers continually reframed the problem, constantly questioning the underlying assumptions during the design process.

Daniel Fallman's work casts HCI as a design discipline [12]. He describes the research performed by engineers and behavioral scientists as "design-oriented research." Researchers engage in designing and making prototypes in order demonstrate a research contribution. In this case, the research community benefits from the processes of design and design thinking because they lead to better research prototypes.

Christopher Alexander's work on Pattern Languages represents an example of how research performed by design researchers on design methods has had an impact on the HCI community. His work asks design researchers to examine the context, system of forces, and solutions used to address repeated design problems in order to extract a set underlying "design patterns", thereby producing a "pattern language" [1]. The HCI community has embraced this approach to address design of web sites [24]. The method turns the work of many designers addressing the same interaction problems into a discourse for the community, allowing interaction designers to more clearly observe the 
formation of conventions as the technology matures and is reinterpreted by users.

\section{The Artifact as a Part of Interaction Design Research}

Daniel Fallman describes the HCI development process used today as research-oriented design to describe the research performed to influence the design of commercial products [12]. Brenda Laurel's book, Design Research: Methods and Perspectives, also describes how interaction designers can perform research as they practice design to better ground their process and to hopefully increase the chances for success of a product in the marketplace [15]. Through this process, HCI practitioners and interaction designers work together as team members, keeping the needs of the user in focus for the entire development team. While both represent a combination of research and making, the focus is still on design as a practice and not as a research discipline that makes contributions of knowledge.

At last year's CHI conference a paper argued against a commonly held belief in the HCI research community that design is a "Black Art" [25]. The authors argued instead that interaction design performed in a research context employs a set of rational judgments. The case documented in this paper places interaction design in the context of HCI research and interaction designers as collaborators with researchers. However, in this specific case, the designers work in service of research, with the goal of creating a research prototype that more clearly communicates the research contribution. We certainly see this type of collaboration as important to the ongoing relationship between researchers and designers, but push for additional collaborations where designers also participate in research and engage research questions specific to interaction design.

Critical design presents a model of interaction/product design making as a model of research [9]. Unlike design practice, where the making focuses on making a commercially successful product, design researchers engaged in critical design create artifacts intended to be carefully crafted questions. These artifacts stimulate discourse around a topic by challenging the status quo and by placing the design researcher in the role of a critic. The Drift Table offers a well known example of critical design in HCI, where the design of an interactive table that has no intended task for users to perform raises the issue of the community's possibly too narrow focus on successful completion of tasks as a core metric of evaluation and product success [10].

Finally, in their book, The Design Way, Harold Nelson and Erik Stolterman frame interaction design-and more generally the practice of design - as a broad culture of inquiry and action. They claim that rather than focusing on problem solving to avoid undesirable states, designers work to frame problems in terms of intentional actions that lead to a desirable and appropriate state of reality. Design is viewed as a unique way to look at the human condition, and is understood through reflective practice, intellectual apperception, and intentional choice. The practice of design is framed as encompassing the real, the true, and the ideal; design research is framed as research on a condition that arises from a number of phenomena in combination, rather than the study of a single phenomenon in isolation. Our model of interaction design research in HCI attempts to formalize many of their ideas in a single method tailored to fit within the context of the HCI research community. We do not view our model as the only way for interaction designers to perform research, but as one of many.

Our model of design research advances the work of the design research community by expanding their focus on methods and analysis of artifacts to include making as a method of inquiry in order to address wicked problems. Our model builds on the current relationship design has with the HCI community by building on Alexander's pattern language model as a method of making research findings actionable by the HCI practice community. Finally our model adds a counterpoint to critical design's focus on design research in the role of critic, by creating a role for the design researcher to be an equal collaborator with $\mathrm{HCI}$ engineering and behavioral science researchers.

\section{INTERVIEWS}

Interviews were conducted within and outside of the discipline of interaction design to understand how collaborations between design and HCI evolve, and to iteratively test our model in progress.

\section{Interaction designers on design and design research}

In our interviews with designers we probed on the value design brings to HCI, and three main themes emerged. First, participants noted that interaction designers brought a process for engaging massively under-constrained problems that were difficult for traditional engineering approaches to address. Second, designers brought a process of integrating ideas from art, design, science, and engineering, in an attempt to make aesthetically functional interfaces. One described this process as similar to composing music or conducting a symphony, where the job is to bring out the richness in a range of voices to make a singular thing. Third, designers brought empathy for users as a part of the process. In addition to considering their needs and desires from an external-observer's perspective, designers worked to also embody the people they made things for.

The designers we spoke with described their early days of collaborating with HCI and software developers, where they were often brought in at the end of the process and asked to make the interface "pretty". In attempting to improve the designs, they were often frustrated that the suggestions they made, which often seemed obvious design improvements, could not be made because they came too late in the development process. However, over time, designers moved from a consultant role at the end of a project to team members working throughout the software design and development cycle. 
Our interviewees suggested that recently, the shift from a more narrow focus on work to a broader view of interaction in people's lives has increased the role of designers in $\mathrm{HCI}$ research and practice. Industrial designers, communication designers, and newly minted interaction designers all began to play more important roles in the invention and development of radically new artifacts meant to address a broad set of problems and opportunities.

Our interviews with leading interaction designers showed that while they have strong agreement about the role design plays and the benefits it brings to HCI practice, designers lack clarity on what design research is or should be with respect to HCI research. In all cases our questions about design research performed outside of a specific design case caught our participants off guard. However, through probing on this issue, three roles for design to play in research emerged: (i) design researcher in service of a research community - working to help researchers ground and frame problems and communicate the impact; (ii) design researcher as critic of the HCI community-making artifacts that stimulate discussion of critical issues; and (iii) design researcher as pattern finder, finding patterns that lead to pattern languages.

One challenge a few interviewees noted for designers participating in research comes from the consultancy model that drives most design work. Since the majority of design research is paid for by the development industry, it is unlikely that this information, which provides a significant competitive advantage, would be openly shared.

\section{$\mathrm{HCl}$ researchers on design and design research}

While interaction designers could articulate their role within an HCI team, researchers were far less articulate about the role of interaction design. In our interviews with leading HCI researchers, we heard views of design as "the discovery of mental models", "a discipline focused on the whole instead of the parts", and "desire to understand users". However, the dominant view was that designers focused solely on the surface structure, or the visual aesthetics of software and hardware artifacts. This idea of design and designers as having a focus on decoration is a commonly held belief of design by most people [5].

When asked about what design research is and what design researchers do, the HCI researchers we interviewed had no concrete ideas. This is not surprising given the lack of clarity within the interaction design community on what design is. Instead, a common theme we heard was that it was up to the interaction designers working in research to invent what design research should be within the context of HCI.

\section{A MODEL OF INTERACTION DESIGN RESEARCH WITHIN HCI RESEARCH}

Our research model attempts to unite and advance the findings from the literature review and interviews described above in a format that complements current methods of HCI research. It follows from Christopher Frayling's concept of conducting research through design [14] where design researchers focus on making the right thing; artifacts intended to transform the world from the current state to a preferred state.

In our model (Figure 1), interaction design researchers engage wicked problems found in HCI. Examples of wicked problems include: (1) The design of smart home services for families where parents address the paradox of wanting to care and protect their children while also wanting to make them independent and children face the paradox of desiring the comfort and security their home and family provide while also wanting to step out and discover and invent who they are and might be. (2) The role of ubiquitous, assistive technology in aiding an elderly population to "age in place" in their own homes. It is wicked in that the stakeholders have conflicting goals including adult children who often want their parents out of the home in an environment that can better ensure their safety, and elder parents who have huge identity investments in their homes, and desire to remain, even when doing so creates tremendous social isolation.

Using our model, interaction design researchers integrate the true knowledge (the models and theories from the behavioral scientist) with the how knowledge (the technical opportunities demonstrated by engineers). Design researchers ground their explorations in real knowledge produced by anthropologists and by design researchers performing the upfront research for a design project. Through an active process of ideating, iterating, and critiquing potential solutions, design researchers continually reframe the problem as they attempt to make the right thing. The final output of this activity is a concrete problem framing and articulation of the preferred state, and a series of artifacts-models, prototypes, products, and documentation of the design process.

This research through design approach produces several beneficial contributions for the HCI community. First, design researchers identify opportunities for new technology or for advancements of current technology that will have significant impact on the world. This type of design research provides research engineers with inspiration and motivation for what they might build. Design researchers also undertake problem framing that helps identify important gaps in behavioral theory and models. In evaluating the performance and effect of the artifact situated in the world, design researchers can both discover unanticipated effects and provide a template for bridging the general aspects of the theory to a specific problem space, context of use, and set of target users. 


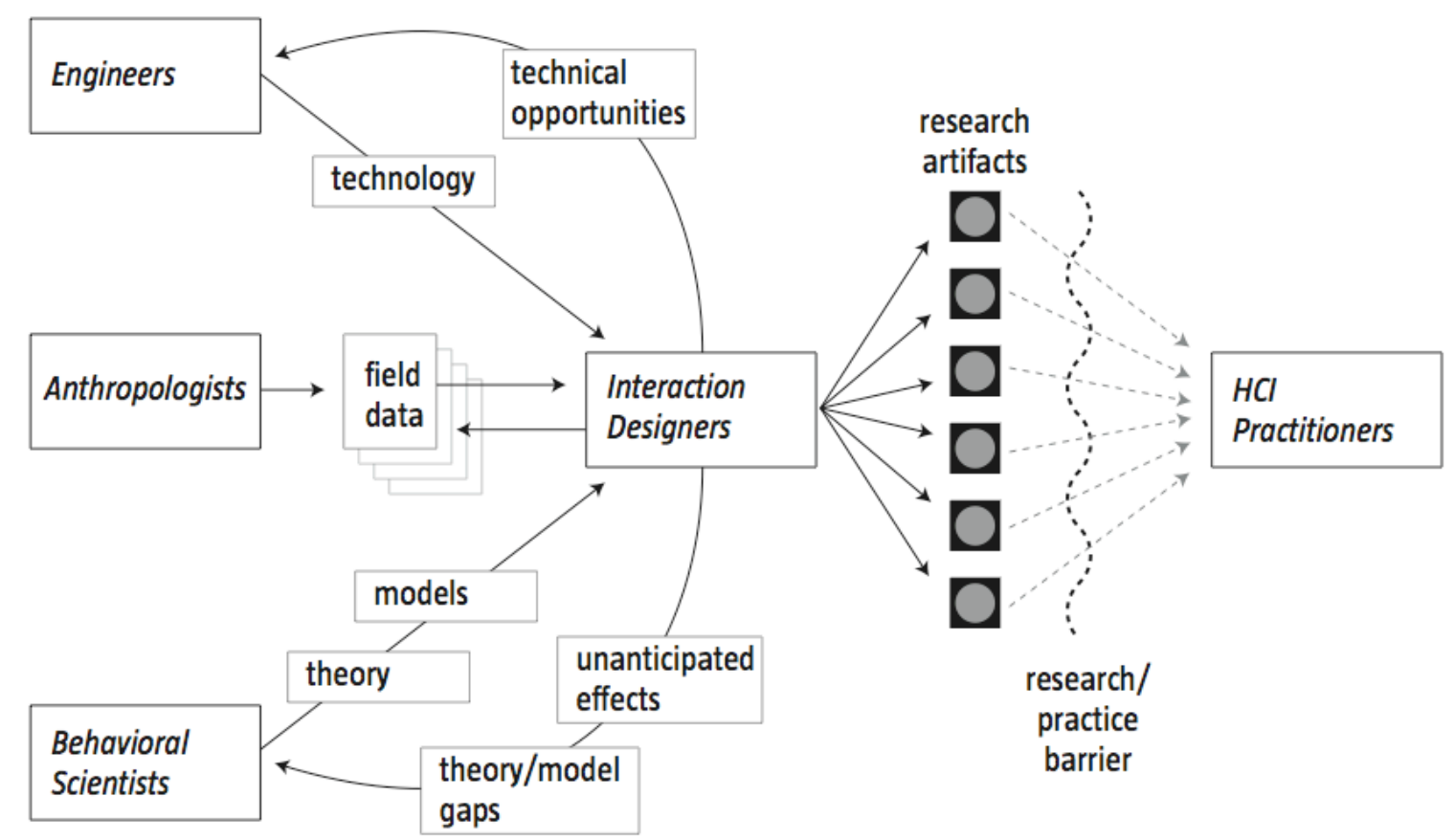

Figure 2. An illustration of the pathways and deliverables between and among Interaction Design Researchers and HCI Researchers. The model emphasizes the production of artifacts as vehicles for embodying what "ought to be" and that influence both the research and practice communities.

Second, interaction design researchers create artifacts provide concrete embodiments of theory and technical opportunities. These design exemplars then become an appropriate conduit for the transfer of $\mathrm{HCI}$ research to the practice community. Design artifacts are the currency of design communication. In education they are the content that teachers use to help design students understand what design is and how the activity can be done [7]. In research, they describe a vision of a preferred state, increasing the chance for knowledge transfer to the research, practice, and education communities. Through exposure to the ideas in the artifacts, the practice community can more easily observe the value of different theories, models, and technology, and this can motivate them to follow the threads back to the original research that might most impact their work.

Third, use of this model results in holistic research contribution that reveals the framing of the problem and the balance the researchers have made between the intersecting and conflicting perspectives. The idea of contributing a whole closely resembles the work of systems engineers in HCI who focus on building whole systems. The Aware Home constructed at Georgia Tech provides a good example [11]. In this case the novelty was not in the construction of the individual elements, but in the integration of many technical research contributions from a variety of disciplines, into a single working system. The difference between this type of contribution and the design research contributions we propose involve both the intent and the process of the research. In making a technical contribution of a whole, engineers first develop a specification of what they need to make to meet a specific need. Next, they take a research focus asking questions such as can this be built? Is there a better way to build this?

In proposing a model of design research with a focus on the production of artifacts, we build on Nigel Cross's idea that design knowledge resides in the product [7]. The artifact reflects a specific framing of the problem, and situates itself in a constellation of other research artifacts that take on similar framings or use radically different framings to address the same problem. These research artifacts provide the catalyst and subject matter for discourse in the community, with each new artifact continuing the conversation. When several related research artifacts have been created, then researchers can use more traditional design research methods to analysis the artifacts and search for similar approaches designers have taken in addressing common problems. The artifacts made through design research have the potential to become pre-patterns [6] from which design patterns [1] can begin to emerge.

Our model departs from the roles of the design researcher discovered in our literature review and interviews: (i) design researcher as member of design practice team doing upfront project research; (ii) traditional knowledge producing design researcher studying design process and analyzing artifacts to discover patterns; (iii) design researcher as critic; and (iv) design research as framing and communication consultant in service of other researchers. Using our model, design researchers work in a way very 
similar to design practitioners, applying their strength at addressing under constrained problems. This is in no way intended to discount the other design research roles that have already had significant impact on HCI. Instead, we are proposing an additional model of design research that seems particularly suited for interaction design researchers working in HCI research and allows design researchers to work more as a collaborative equal with other $\mathrm{HCI}$ researchers. An obvious criticism of this model is how in its use design researchers can distinguish their contributions as research and not as practice. This is a concern raised by Nigel Cross, who cannot consider normal works of practice to be regarded as research contributions [7].

We differentiate research artifacts from design practice artifacts in two important ways. First, the intent going into the research is to produce knowledge for the research and practice communities, not to make a commercially viable product. To this end, we expect research projects that take this research through design approach will ignore or deemphasize perspectives in framing the problem, such as the detailed economics associated with manufacturability and distribution, the integration of the product into a product line, the effect of the product on a company's identity, etc. In this way design researchers focus on making the right things, while design practitioners focus on making commercially successful things.

Second, research contributions should be artifacts that demonstrate significant invention. The contributions should be novel integrations of theory, technology, user need, and context; not just refinements of products that already exist in the research literature or commercial markets. The contribution must demonstrate a significant advance through the integration. This aspect of a design research contribution makes particular sense in the interaction design space of HCI. Meteoric technological advances in hardware and software drive an aggressive invention of novel products in HCI and interaction design domains that are not as aggressively experienced by other design domains. While product designers might find themselves redesigning office furniture to meet the changing needs of work, interaction designers more often find themselves tasked with inventing whole new product categories.

Our model of design research allows interaction design researchers to do what designers do best: to study the world and then to make things intended to affect change. Our model provides a new channel for the power of design thinking, desired by many disciplines, to be unleashed as in a research context. Design researchers can contribute from a position of strength, instead of aping the methods of other disciplines as a means of justifying their research contribution.

\section{CRITERIA FOR EVALUATING INTERACTION DESIGN RESEARCH WITHIN HCI}

Many design researchers have made contributions using a research through design approach. While the idea is not new, within the HCI and interaction design research community, there is no agreed upon standard of what research through design means nor what a high quality contribution should be. To help to formalize this research method, we propose a set of criteria, or four lenses for evaluating an interaction design research contribution: process, invention, relevance, and extensibility.

Process: One of the critical elements for judging the quality of an interaction design research contribution is the process. Like anthropologists making contributions in this sciencedominated domain, there is no expectation that reproducing the process will produce the same results. Instead, part of the judgment of the work examines the rigor applied to the methods and the rationale for the selection of specific methods. In documenting their contributions, interaction design researchers must provide enough detail that the process they employed can be reproduced. In addition, they must provide a rationale for their selection of the specific methods they employed.

Invention: The interaction design research contribution must constitute a significant invention. Interaction design researchers must demonstrate that they have produced a novel integration of various subject matters to address a specific situation. In doing so, an extensive literature review must be performed that situates the work and details the aspects that demonstrate how their contribution advances the current state of the art in the research community. In addition, in articulating the integration as invention, interaction designers must detail how advances in technology could result in a significant advancement. It is in the articulation of the invention that the detail about the technical opportunities is communicated to the engineers in the HCI research community, providing them with guidance on what to build.

Relevance: Scientific research has a focus on validity. In engineering, this often means a demonstration of the performance increase or the function of their contribution. In behavioral science, validity means an experiment that disproves the null hypothesis. In both cases, the work must be documented in such a way that peers can reproduce the results. As mentioned above, this does not make sense to have as a requirement for a research through design approach. There can be no expectation that two designers given the same problem, or even the same problem framing, will produce identical or even similar artifacts. Instead of validity, the benchmark for interaction design research should be relevance. This constitutes a shift from what is true - the focus of behavioral scientists, to what is real- the focus of anthropologists. However, in addition to framing the work within the real world, interaction design researchers must also articulate the preferred state their design attempts to achieve and provide support for why the community should consider this state to be preferred.

Today, many design research contributions claiming to follow a research through design approach neglect to cast the work in terms of relevance. The design researchers 
follow a design process, but the motivation for their work, the detail on current situation, and on the preferred state are missing. Without this critical component, a research through design approach appears to be self-indulgent, and personal exploration that informs the researcher but makes no promise to impact the world.

Extensibility: The final criterion for judging successful design research is extensibility. Extensibility is defined as the ability to build on the resulting outcomes of the interaction design research: either employing the process in a future design problem, or understanding and leveraging the knowledge created by the resulting artifacts. Extensibility means that the design research has been described and documented in a way that the community can leverage the knowledge derived from the work.

\section{EXAMPLES OF INTERACTION DESIGN RESEARCH WITHIN HCI}

In order to demonstrate how the lenses might work for evaluating the quality of interaction design research in HCI, we provide examples of three interaction design cases that help illustrate different aspects of this model.

\section{XEROX reprographics}

FitchRichardsonSmith's work with Xerox in the early 1980s on the interaction design of reprographics machines provides an early example of research through design that produced design exemplars and a design language (an intentional pattern language) that can still be seen today in the interaction and behavior of copiers and printers. The design process was documented in an extended rationale, called Principles for Constructing Communicative Objects and Object Systems for Interactive Dialogs, and detailed the design and rationale for every element of a machine to support positive interaction [28].

Prior to this work, reprographics machines used in offices generally had a key operator: a trained technician that held the key to operate, maintain, and repair the machine. Design researchers working on this project reframed the problem from making a machine that was easier for a key-operator to maintain to making a machine that any office worker could walk up to, use, and fix if it had a paper jam. The prototypes produced (Figure 3) illustrated the idea that people could learn to operate the machines as they used them-rather than being trained, which was unheard of in the industry at that time. The design language included the use of green on the copy button and on the edge of the glass panel to indicate points of entry, and the color blue to indicate where users should interact with paper. Lighter shades indicated areas of frequent interaction and darker shades indicated areas with less frequent use. Texture indicated specific touch points. Finally, the prototypes provided concrete illustrations of how to provide instructions at the point of need. Evaluations of the prototypes revealed a shift in work practice that came about as a result of the new way of interacting with the machines [20].

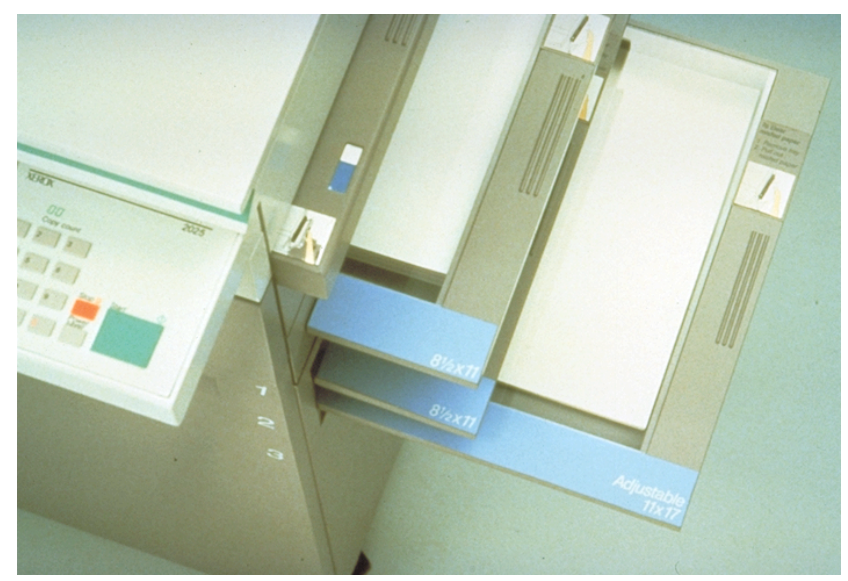

Figure 3. Xerox prototype machine.

In terms of invention, this work demonstrated an integration of the latest cognitive research on how people learn to interact with systems. In terms of relevance, it connected with the increasing need in the work place to empower workers to take more ownership and responsibility for the individual documents they were working on. One of the most valuable contributions was extensibility. The Xerox guidelines and rationale document communicated reusable information for extensions in design [27] but the machines themselves became objects that could be read by other designers outside of Xerox. This worked to transfer the knowledge to the practice community. Today, elements and resources from this interaction design research project can still be seen in almost every copier and printer.

\section{Philips vision of the future}

In 1995, Philips Design's Vision of the Future project explored possibilities for life and technology in the near future. Using a rigorous design process documented in the book Vision of the Future [19], this project examined how advances in technology would change family life along with other aspects of society. Multidisciplinary teams were brought together to propose directions for new products and services in four different domains of life: personal, domestic, public, and mobile. In terms of relevance, the work detailed how changes to traditional forms and behaviors of technical products technology could allow products to more easily integrate into the social life of people outside of work environments. For example, Figure 4 shows a mobile communication device housed in an aesthetic form not unlike a flower vase. The novel designs clearly had the intention of improving the quality of people's lives and provided a view of a preferred state. The work and the design process have also proven to be extensible, as numerous undergraduate and graduate programs in interaction design have imitated the project. 


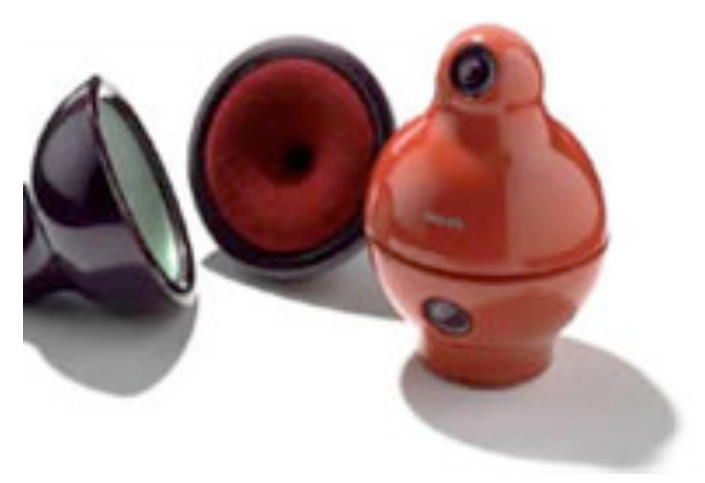

Figure 4. Concept from Philips vision of the future project.

\section{Apple Guides}

This research through design project helps illustrate how interaction design research can feed back ideas to the HCI research community. In designing an interface to a multimedia database, the design team used theory from cognitive psychology to address the real world issue of people getting lost in hypertext interfaces [18]. The team chose to use black and white renderings of people dressed in historic costumes and set in historic contexts.

In evaluating this interface to see if the guide improved the navigation of the content, the design team discovered an unanticipated of effect. Participants no longer viewed the content as having the voice of an unbiased encyclopedia. Instead, they felt the content represented the opinion of the individual guide. Through dissemination of these evaluation findings, this design through research project helped to stimulate new technical research on the underlying technology to produce embodied agents and new behavioral research to understand the effect embodied agents had on users.

\section{CONCLUSION}

This paper has presented two years of iterative design efforts to explore and advance methods for interaction design researchers to make design research contributions that both integrate with and benefit the HCI research and practice communities. The work has resulted in a new model of interaction design research within HCI that allows design researchers to collaborate on an equal footing with HCI engineering and behavioral science researchers. In addition, it provides a set of critical lenses for evaluating what constitutes a good interaction design research contribution for researchers following this model.

The model provides five main benefits. First, it allows the HCI research community to engage with wicked problems that cannot be easily addressed through science and engineering methods. Second, it feeds back technology opportunities to the engineers and gaps in behavior theory and unexpected behaviors to the behavioral scientists, motivating new research. Third, it provides a new method for transferring knowledge produced in the HCI research to the HCI practice community, potentially increasing the likelihood this knowledge will move into products in the world. Fourth, it allows interaction designers to make research contributions that take advantage of the real skill designers possess - reframing problems through a process of making the right thing. Fifth, it motivates the HCI community to discuss preferred states and to reflect on the potential impacts research might have on the world.

We hope that in proposing this model, we can begin a serious discussion of the role of design and design thinking in HCI research. We will continue to evaluate and refine our model with practitioners and researchers. Additionally, we hope to formulate some changes to both HCI and interaction design education that will allow interaction design research to continue to grow in importance.

\section{ACKNOWLEDGEMENTS}

We wish to thank our colleagues at Carnegie Mellon's Human-Computer Interaction Institute (HCII) and at the School of Design for their participation, insights, and patience. In addition, we would like to thank Professor Dan Sieworiek, the director of the HCII, for his championing and financial support of this work.

\section{REFERENCES}

1. Alexander, C., Ishikawa, S., Silverstein, M., Jacobson, M., Fiksdahl-King, I., Angel, S. A Pattern Language: Towns, Buildings, Construction. Oxford University Press, 1977.

2. Apple Computer, Inc. Macintosh Human Computer Interface Guidelines, Addison-Wesley Professional, Reading, MA, 1992.

3. Bayazit, N. Investigating Design: A Review of Forty Years of Design Research. Design Issues 20, 1 (2004), 16-29.

4. Buchanan, R. Design Research and the New Learning. Design Issues 17, 4 (2001), 3-23.

5. Blevis, E., Lim, Y.K., \& Stolterman, E. Regarding Software as a Material of Design. Proc. of Wonderground, Design Research Society, (2006).

6. Chung, Eric, Jason I. Hong, James Lin, Madhu K. Prabaker, James A. Landay, and Alan Liu. Development and Evaluation of Emerging Design Patterns for Ubiquitous Computing. Proc. DIS 2004, ACM Press (2004), 233-242.

7. Cross, N. Design Research: A Disciplined Conversation. Design Issues 15, 2 (1999), 5-10.

8. Cross, N. Designerly Ways of Knowing: Design Discipline Versus Design Science. Design Issues 17, 3 (2001), 49-55.

9. Dunne, A., Raby. F. Design Noir: The Secret Life of Electronic Objects. Birkhäuser, Basel, Switzerland, 2001.

10. Gaver, WW., Bowers, J., Boucher, A., Gellerson, H., Pennington, S., Schmidt, A., Steed, A., Villars, N., Walker, B. The drift table: designing for ludic 
engagement. Ext. Abstracts CHI '04, ACM Press (2004), 885-900.

11.Kidd, C.D., Orr, R., Abowd, G.D., Atkeson, C.G., Essa, I.A., MacIntyre, B., Mynatt, E.D., Starner, T., Newstetter, W. The Aware Home: A Living Laboratory for Ubiquitous Computing Research, Proc. of the Second International Workshop on Cooperative Buildings, Integrating Information, Organization, and Architecture, (1999) 191-198.

12. Fallman, D. Design-Oriented Human-Computer Interaction. Proc. CHI 2003, ACM Press (2003), 225232.

13. Fallman, D. Why Research-Oriented Design Isn't Design-Oriented Research. Proc. NordiCHI 2005, Umea Institute of Design Press (2005).

14. Frayling, C. Research in Art and Design. Royal College of Art Research Papers 1, 1 (1993),1-5.

15. Laurel B. Design Research: Methods and Perspectives. MIT Press, Cambridge, MA, 2003.

16. Löwgren, J. Applying Design Methodology to Software Development. Proc. of DIS 1995, ACM Press (1995), 87-95.

17. Nelson, H.G. and Stoltermann, E. The Design Way: intentional change in an unpredictable world. Educational Technology Publications, Englewood Cliffs, NJ, 2003.

18.Oren, T., Salomon, G., Kreitman, K., Don, A.: Guides: Characterizing the Interface. In (Eds: Laurel, B.): The Art of Human-Computer Interface Design, Addison-Wesley (1990) 355-365.

19. Philips Design, Vision of the Future $V \& K(1995)$
20. Rheinfrank, J., Hartman, W., Wasserman, A., Design for usability: crafting a strategy for the design of a new generation of Xerox copiers, Usability: turning technologies into tools, Oxford University Press, Inc., New York, NY, 1992.

21. Rittel, H.W.J., Webber, M.M. Dilemmas in a General Theory of Planning. Policy Sciences 4, 2 (1973), 15566.

22. Schön, D.A. The Reflective Practitioner: How professionals think in action. Temple Smith, London, 1983.

23. Simon, H.A. The Sciences of the Artificial, MIT Press, Cambridge, MA, 1969.

24. van Duyne, D.K., Landay, J.A., Hong, J. I. The Design of Sites: Principles, Processes, and Patterns for Crafting a Customer-Centered Web Experience, Addison-Wesley, Reading, MA, 2003.

25. Wolf, T.V., Rode, J.A., Sussman, J., Kellogg, W.A. Dispelling Design as the 'Black Art' of Chi. Proc. of CHI 2006, ACM Press (2006), 521-530.

26. Wright, P., Blythe, M., McCarthy, J. User Experience and the Idea of Design in HCI. Lecture Notes in Computer Science, Stephen W. Gilroy and Michael D. Harrison eds. Springer, Berlin/Heidelberg (2006). 1-14.

27. Xerox Corporation. Design Guidelines: Industrial design and Human Factors for Reprographics Products (1985).

28. Xerox Corporation. Principles for Constructing Communicative Objects and Object Systems as Interactive Dialogs (1985). 